\title{
Networked Expertise Empowering Brazilian Teachers' Professional Development and Pedagogical Change
}

\author{
Essi Ryymin, Irma Kunnari, Brian Joyce, Marja Laurikainen \\ Häme University of Applied Sciences (HAMK), Finland
}

\begin{abstract}
The aim of this study is to research the 15 Brazilian teachers' experiences during a Finnish teacher training program, in which the focus was on supporting teachers' professional development and creating competences to make pedagogical change. The preliminary findings suggest that the networked expertise plays a crucial role in the teachers' professional development and in re-designing their current educational practices. However, the deliberative pursuit of collaborative knowledge building and supportive networks for contextualizing development in the Brazilian learning environment after the training program is needed for sustainable professional growth.
\end{abstract}

\section{Introduction}

The ongoing research of Häme University of Applied Sciences (HAMK) aims to examine the development of networked expertise and collaborative knowledge building of Brazilian teachers during their professional development program in Finland. The goal of the research is to investigate the Brazilian teachers' most meaningful learning experiences related to theoretical, practical, self-regulative and sociocultural knowledge building [1] and what kinds of challenges Brazilian teachers experience in applying educational innovations in their learning environment. In addition, the project is interested in analyzing the Brazilian and Finnish educators' joint educational initiatives.

In Finland, and globally, teachers' education is expected to have an impact on adapting to rapidly transforming global environments and aiming at solving emergent problems and constantly pursuing novelty and innovation. Notions of 'change' and 'innovation' are inextricably linked [2] and many educational developers view their role as being fully or partially responsible for encouraging innovation in teaching and learning [3]. Students' learning processes are organized integrating education and the world of work, shifting learning paradigms; the competences needed in the future have transformed the learning methods and environments from a teacher-centered to learner-centered model of education.

As the key players in educational change, teachers have encountered the demand of big transformation in their profession, and the need has been recognized at a national level in many countries. That is why the School of Professional Teacher Education of Häme University of Applied Sciences (HAMK) in Finland offers international professional development programs for vocational and professional teachers.

According to Kunnari and Ilomäki [4] teachers' personal experiences, sources of interest and enthusiasm, as well as the challenges they face and the organizational support needed, are intertwined with and a fundamental part of educational change. Teachers' personal development, social interaction and work conditions form an integrated entity, with all parts interconnected. Sustainable change is created by focusing on all these parts. In previous studies [4], [5], [6] it has been found that a collaborative culture is essential to the diffusion of the educational innovation.

However, when investigating teachers' professional development it is important and meaningful to overcome individualistic approaches and reflect the teachers' professional development in the networks and in the context of networked expertise [7].

Hakkarainen and his team [8] have developed a theoretical and methodological framework to examine networked expertise. By networked expertise Hakkarainen means higher-level competences that arise, in appropriate environments, from sustained collaborative efforts to solving problems and building knowledge together. Networked expertise is relational

in nature; emerging from the fine-tuning of individual competencies to specific requirements of collaborative activity, and considered to represent a joint or shared competence of communities and organized groups of experts and professionals [8].

Investigations reveal that after reaching expertlevel, people are able to produce better solutions than novices, identify more complex and meaningful patterns, analyze problems qualitatively, reflectively assess their own reasoning processes, and utilize sophisticated strategies by relying on minimal intellectual efforts [9]. Such personally cultivated competencies do not arise inside the experts' minds but represent cultural-historical developments of domain of knowledge and their capabilities are embodied in shared practices of expert communities and networks [9]. According to Hakkarainen [8] and Paavola, Lipponen and Hakkarainen [10] professional activity increasingly takes place in knowledge communities and networks, relying on 
dynamically evolving epistemic practices, rather than stable procedures, or given constellations of skills. The term 'knowledge' is used in the broadest sense, to include what is explicit official discourse (for example, approved texts); what is implicit, informing one's habits in expert working; and what underlies the competencies of experts, for example, so called 'procedural knowledge' [11]. Current theories of social practices relevant for professional expertise [12] highlight both the inseparability of knowing and doing and the creative and improvisational aspect of practice.

The ongoing research referred to in this article aims to examine networked expertise of Brazilian teachers during their professional development program in Finland. The goal of the research is to investigate the meaning of networked expertise in teachers' professional development process and in their process of implementing new pedagogical practices in their own school context, in pedagogical change. The research questions of the current study are: 1) What is the meaning of networked expertise in Brazilian teachers' professional development? 2) What is the meaning of networked expertise for Brazilian teachers' when implementing pedagogical change?

\section{The Context of the Research}

The context of the study is a tailored Finnish vocational teacher-training program for Brazilian teachers. The program is called VET Teachers for the future ${ }^{\circledR}$ - Professional Certificate Programme and it was carried out in 1.2.-11.12. 2015. The program scores 30 ECTS. The research project in progress examines the professional development of 15 Brazilian teachers, during the 9-month training program. The implementation of the 9-month program was divided into two parts. During the first 5 months (1.2.-30.6. 2015) Brazilian teachers study in the Finnish learning environment, at Häme University of Applied Sciences (HAMK). After this period, they returned back to their own working environments and applied the new pedagogical knowledge into their own educational context for 4 months (1.8.-30.11.2015) with the support of Finnish teacher educators' online guidance.

The goal of the training program is to empower the participants to collaboratively rethink and design education and learning environments to respond better to their on-going regional, and future challenges. The main contents of the program include activating and student-centered learning methods, models for educational change, learning community building, and digitalization of education. There are many similar challenges globally in terms of developing teachers' competence and networked expertise to apply educational change. Teachers need to be continuous learners, co-creators and 'change agents' in their learning and working environment. In order to achieve professional development needed, the integration of teachers' theoretical, practical, self-regulative and sociocultural knowledge is essential [1]. That is why collaboration and networking is consciously utilised during the training, as a tool to develop and to create competences for sustainable pedagogical development. The participants practiced collaborative learning, dialogical learning and they were encouraged to create and strengthen their own personal networks for their work as teacher and as a pedagogical developer.

The participants of the study are 15 Brazilian teachers from the following fields of education: biotechnology, agricultural engineering, agronomy, computer science, chemistry, mathematics, linguistics, educational sciences and business administration. The group consisted of six females and nine males. Their ages varied from 29 to 52 , their average age being 39 years. The total number of participants of the training were 16 , but one student refused to complete research.

The participants worked in the Federal Institutes in Brazil, which are institutions for higher, basic and professional education specialized in offering vocational and technological education. The purpose of the Federal Institutes is to answer to the social and economic demands of the regions by using applied research to boost innovations and the local development as well as to create linkage between different levels of vocational education.

Only one of the participants had some previous pedagogical training or qualification prior to the VET Teachers for the Future program. However, three of them had experience in the development and use of new technologies in education as well as in the design of new learning environments. One of them was a pedagogical area coordinator of the technical course and two of them had some experience in training teachers.

\subsection{Methods and analysis}

In the ongoing research process the data consist of different qualitative and quantitative material gathered during and after the program: surveys, interviews, development work and several forms of written data in database, e.g. learning diary blogs and individual and collective learning assignments.

However, this study article is focused on data gathered using a semi-structured questionnaire at the end of Finnish 5-months section of the training program. The questionnaire inquired especially about the most meaningful and important learning experiences of the teachers and their plans of implementation when returning to their Brazilian learning environment. The questionnaire was sent to the participants by email using Webropol 
application. The data was qualitatively content analysed [13]. The process of analysing the content was iterative explanation building, aiming to explain the causalities of the real-life processes. The units of the analysis were the participants' opinions concerning the most meaningful and important learning experiences.

Furthermore, in future, social network analysis [14] is planned to gather more detailed information of internal networking relations of teachers' knowledge-sharing networks.

\section{Study Results}

In this study, we were interested in studying the meaning of networked expertise for the Brazilian teachers. In the following, we are presenting the Brazilian teachers' own experiences, what was the meaning of the networked expertise for their own professional development and the meaning for their pursuing the pedagogical change.

\subsection{The meaning of networked expertise in Brazilian teachers' professional development}

The Brazilian teachers participating in this study recognized the networked expertise, described as a learning community, as a very meaningful part of a good educational environment. They started to develop the idea of importance of collaborating and networking already during their process in Finland. Among the answers to the inquiry about most meaningful learning experience, collaborative work, networking and building knowledge together with other teachers were mentioned several times. The networked way of working started to become a new mindset for the participants.

"The most meaningful learning outcome for myself was to be conscious about how can I contribute to the development of vocational education in my country. The interaction with the team was very productive, and I could share some thoughts I had, and at the same time learn a lot with other experiences, from the team and from my colleagues from Brazil."

"It was a period of profound reflections on the role of educator to me. The intensity of the program was an important factor, allowed several individual and collective reflections. Contact with other teachers was also very constructive and benefic to the whole group. We learned a lot with each other. The most significant learnings to me were related to way of thinking, mind-set."

The teachers also started to see themselves as networkers and collaborators, the new role as a change agent began to grow during the training. Besides learning the student-centered methods, they also learned the importance of collegial sharing and community building.

"In particular, I could begin the contact with some issues related to the curriculum construction and, back to my institute, I will try to discuss about the curricula we have there. Last week I applied to work in the Centre for Assistance to People with Special Needs of my campus, where I hope to contribute sharing what I saw in Finland and training teachers to deal with this reality."

"The most meaningful learning outcomes were: understand the role of the student in the learning process, sharing responsibilities with the teachers and the conditions for this learning to happen, as one example, using student centred- approaches."

"How to integrate the community in the (learning) project."

The guided and collaborative learning with deliberate knowledge building, joint reflections and dialoguing process of the training was experienced as meaningful for many teachers.

"I really appreciated the way the program was developed, since it was flexible and respected everyone's background. The group could construct meanings together and the mediators were respectful and worked to further our knowledge."

"I am learning a lot...in all situations...in street, in classroom, outside...I made different connections between what I heard about education in Finland and what I saw and talking with students."

"I liked very much dialogical method. It is cooperative activity of reflection, transformation and sharing of idea too. Turn into new ideas through collective reflections in the conversation. On the other hand, a 


$$
\begin{aligned}
& \text { methodology that enables people } \\
& \text { "thinking and learning together" }
\end{aligned}
$$

Besides collegial networking, connecting with the students in a new way was recognized as important for teachers. Part of the networked expertise of teachers is the competence of creating students' participation. In the teachers' most meaningful learning experience, students' participation was mentioned several times. In addition, building networks for students to learn competences in real-life environments was experienced as important.

"The importance involve active participation of students in the project activities"

"How to make learning more meaningful for students and related to real-world problems."

In the beginning of the training program, the Brazilian teachers were not so familiar with studentcentered collaborative learning methods and they were expressing that the individual teacher-centered working model was quite common in their own school context. Therefore, the idea of networked expertise can be very empowering for them to encounter new challenges trying to change their own work as a teacher.

\subsection{The meaning of networked expertise for Brazilian teachers implementing pedagogical change}

The Brazilian teachers considered the networked expertise and collegial support as an important catalyst in the pedagogical change in their working and learning environments.

"In my working environment, I see myself as a community builder and multiplier and I know I can contribute to create better learning opportunities to our students. So, what I intend to do is to take the actions to establish a Professional Learning Community. I believe that is the basis of an educational organization. I can't think only of helping students without helping teachers to be more prepared."

"Nowadays, the new dynamic is collaboration. No educational institution can survive without that. Education reflects society and ours is continuously changing in a speed our documents can't follow, our formal "canned" training courses can't follow. As teachers, we face new challenges daily in our classrooms and schools must provide means we can develop to meet our needs."

"But I also wish to cause impacts on a broader scope. Try to engage other teachers to work collaboratively, integrating disciplines and making educational projects together. I will also involve directors and course coordinators to try enlarge the impacts on larger spheres. I desire to expand the results of (my project) through knowledge attained here, and try to involve more students and teachers in the initiative."

"I could list more challenges, but I prefer to focus on the things I can do and to team up with people who are also community builders."

Teachers were also reflecting what kind of personal competences they would need in the dissemination of new pedagogical innovations or trying to make the pedagogical change in their learning context. Some of the replies reflect networked expertise.
"Dealing with resistance and differences among teachers. Raise awareness of the change and the importance of teamwork in the pursuit of better teaching learning process."
"Management of Distance Learning Education Programmes; management of VET Program; negotiation with companies; negotiation with teachers and students using distance learning environments; engaging students in a virtual learning environment; and using English as a second language. These competences are basic to me"
"The capacity of work collaboratively, to know how make open Questions, to use dialogical Methods and patience."

Furthermore, the teachers considered the networking between Finnish and Brazilian partners important for their future actions in pedagogical change. 
"Constant review of the proposed activities; constant upgrade about new tools, new research in education, new methods in education."

"Follow the developed activity as much as possible, but maybe reflecting together and discussing about this."

"Share experiences observed in my institution, find solutions together to problems and obstacles, keep the motivation during project execution."

"The word partner has been widely used, but people are losing the true meaning. I believe that partnership is for life, are those people you can count on, regardless of time, date or distance. This contact connect our minds and resulting in joint projects."

"I guess mainly the motivation and emotional support because we already receive many different materials to support the how-to so now we have to be patient and wise to foster the changes in our environment."

"I think that feedback results achieved, counseling, meetings and feedback of the results on the blog."

In addition, teachers described that many experiences in the Finnish learning culture inspired them to re-design and transform their conceptions and practices of learning, especially school visits, meeting Finnish teachers and practicing new studentcentered methods in training. Networking with the Finnish teachers deepened their reflections of the teacher's role and profession, and possibilities of professional growth. Studying in Finland was a remarkable and memorable formal, non-formal and informal learning experience for the teachers.

Designing the implementation and dissemination of new pedagogical practices for their own schools was considered very challenging. Finnish teacher educators' guidance and encouragement was described essential, in addition to peer guidance and collegial support, in an empowering networked learning community.

\section{Discussions and Conclusions}

The study revealed that the participating 15 Brazilian teachers found several meanings for networked expertise in their professional development, and in the process of pedagogical change. Learning community building was considered important for the professional growth and with a new, networked mindset teachers started to see themselves as networkers and collaborators, and eager to build collegial networks.

The Brazilian teachers expressed that pedagogical change and implementing new pedagogical practices require many advanced competences related to networked expertise. Dialoguing, collegial knowledge sharing, team working and engaging people were mentioned as important capabilities. In addition, pedagogical change requires new skills in building better connections with students.

Networking was also planned to be one of the most important future actions, after the training program. Teachers were planning to expand their networks in Brazil and continue networking with Finnish partners and educators too. The Finnish teacher educators' support was needed in empowering and encouraging teachers to make changes, deepen and evaluate their pedagogical knowledge and performance.

The role of Finnish teacher educators as partners, facilitators and evaluators is important in supporting teachers' professional development after the training program. The role of an international network is to encourage teachers and sustain professional confidence in creating and contextualizing new pedagogical approaches.

In future, it is important to include networked expertise and learning community building to international teacher training programs systematically and intentionally. The higher-level competences and sustained collaborative efforts are needed to solve problems of educational change, and build pedagogical knowledge together. Furthermore, teachers' professional development and aspects of educational change on an organizational level need to be integrated into the training. The sustainable professional development and contextualized pedagogical change requires change management and transformation of educational organizations as well. It is important to research in more detail the implementation of pedagogical practices in authentic Brazilian learning environments and the teachers' experiences of their challenges and successes in the pedagogical change process.

\section{References}

[1] Tynjälä, P., Häkkinen, P. and Hämäläinen R., (2014).TEL@work - towards integration of theory 
and practice. British Journal of Educational Technology. 45(6), 990-1000.

[2] Hannan, A., \& Silver, H., (2000). Innovating in higher education - teaching, learning and institutional cultures. Buckingham: Society for Research into Higher Education and Open University Press.

[3] Gosling, D., (2009). Educational development in the UK: A complex and contradictory reality. International Journal for Academic Development, 14(1), 5-18.

[4] Kunnari, I., and Ilomäki, L., (2014). Reframing teachers' work for educational innovation. Innovations in Education and Teaching International. Routledge.

[5] Fullan, M., (1996). Professional culture and educational change. School Psychology Review, 25, 496-500.

[6] Smith, K., (2012). Lessons learnt from literature on the diffusion of innovative learning and teaching practices in higher education. Innovations in Education \& Teaching International, 49, 173-182.

[7] Ryymin, E., (2008). Teachers' Intelligent Networks. Study of Relationship-based Professional Development supported by Collaborative Learning Technologies. Academic Dissertation. Acta Universitatis Tamperensis 1336. Tampere: Tampere University Press.

[8] Hakkarainen, K., Palonen, T., Paavola, S., and Lehtinen, E., (2004). Communities of networked expertise: Professional and educational perspectives. Advances in Learning and Instruction Series. Amsterdam: Elsevier.

[9] Chi, M., T., H., (2006). Two approaches to the study of experts characteristics. In K. A. Ericsson, N. Charness, P. Feltovich, \& R. Hoffman (Eds.) The Cambridge handbook of expertise and expert performance (pp. 21-30). Cambridge, MA: Cambridge University Press.

[10] Paavola, S., Lipponen, L., and Hakkarainen, K., (2004). Modeling innovative knowledge communities: A knowledge-creation approach to learning. Review of Educational Research, 74, 557576.

[11] Hakkarainen, K., Hytönen, K., Vekkaila, J., \& Palonen, T., Networked expertise, relational agency, and collective creativity, approved manuscript.
[12] Nicolini, D., Gherardi, S., and Yanow, D., (2004). Introduction: Toward a practice-based view of knowledge and learning in organization. In D. Nicolini, S. Gherardi, \& D. Yanow (Eds.), Knowing in organization: A practice-based approach (pp. 331). London: M. E. Sharpe.

[13] Patton, M., Q., (1990). Qualitative evaluation and research methods (2nd ed.). Newbury Park, CA:

[14] Scott, J., (1991). Social network analysis: A handbook. London: SAGE Publications. 